\title{
Weblogs as instruments for reflection on action in teacher education
}

Citation for published version (APA):

Wopereis, I., Sloep, P., \& Poortman, S. (2010). Weblogs as instruments for reflection on action in teacher education. Interactive LearnIng Environments, 18(3), 245-261. https://doi.org/10.1080/10494820.2010.500530

DOI:

$10.1080 / 10494820.2010 .500530$

Document status and date:

Published: 01/01/2010

Document Version:

Peer reviewed version

Document license:

CC BY-NC

Please check the document version of this publication:

- A submitted manuscript is the version of the article upon submission and before peer-review. There can be important differences between the submitted version and the official published version of record. People interested in the research are advised to contact the author for the final version of the publication, or visit the DOI to the publisher's website.

- The final author version and the galley proof are versions of the publication after peer review.

- The final published version features the final layout of the paper including the volume, issue and page numbers.

Link to publication

\section{General rights}

Copyright and moral rights for the publications made accessible in the public portal are retained by the authors and/or other copyright owners and it is a condition of accessing publications that users recognise and abide by the legal requirements associated with these rights.

- Users may download and print one copy of any publication from the public portal for the purpose of private study or research.

- You may not further distribute the material or use it for any profit-making activity or commercial gain

- You may freely distribute the URL identifying the publication in the public portal.

If the publication is distributed under the terms of Article 25fa of the Dutch Copyright Act, indicated by the "Taverne" license above, please follow below link for the End User Agreement:

https://www.ou.nl/taverne-agreement

Take down policy

If you believe that this document breaches copyright please contact us at:

pure-support@ou.nl

providing details and we will investigate your claim.

Downloaded from https://research.ou.nl/ on date: 26 Apr. 2023 


\title{
Weblogs as instruments for reflection on action in teacher education
}

\author{
Iwan G.J.H. Wopereis ${ }^{\mathrm{a}^{*}}$, Peter B. Sloep ${ }^{\mathrm{a}}$ and Sybilla H. Poortman ${ }^{\mathrm{b}}$ \\ ${ }^{a}$ Centre for Learning Sciences and Technologies, Open University of the Netherlands, \\ Heerlen, The Netherlands; ${ }^{b}$ Fontys University of Applied Sciences, Sittard, The \\ Netherlands
}

Iwan Wopereis, Open University of the Netherlands, Centre for Learning Sciences and Technologies, PO Box 2960, 6401 DL Heerlen, The Netherlands. E-mail: iwan.wopereis@ou.nl

\begin{abstract}
This study examined the use of weblogs as a means to promote student teachers' reflective practice. The assumption that weblogs are suitable tools for supporting and stimulating reflection on action in teacher training and consequently for enhancing the students' ability to reflect, was explored. Three groups of student teachers used weblogs during an eight-week internship for reflection on teaching practice. Students were asked (a) to reflect on their own teaching experiences and (b) to provide peer feedback. Analyses of the student contributions show that weblogs are useful for reflection on critical incidents in the classroom and that they can stimulate interconnectivity in groups of students. Unfortunately weblogs do no incite deep reflection or spiral reflection. This can only be the result of explicit reflection instruction. This exploratory study further shows that large-scale quantitative research is needed to back up the premise that weblogs are suitable tools for reflection.
\end{abstract}

Keywords: weblogs; blogs; reflection; teacher education; social networks

\section{Introduction}

During the last decade, the information and communication technology (ICT-) industry has overrun the internet-connected part of society with appealing web-based tools for publishing and exchanging information. User-friendly second generation web-based 'read and write' tools such as social networking sites, folksonomies, wikis, and weblogs (a.k.a. 'blogs'), have been widely adopted for (p)leisure and as such they seem to be powerful tools for informal learning (Alexander, 2006; boyd \& Ellison, 2008). Hence, it is not surprising that actors in the educational arena foresee openings for large-scale implementation of second generation web-based technologies in formal educational practice (Greenhow, Robelia, \& Hughes, 2009; Klamma et al., 2007; McLoughlin \& Lee, 2008; Ravenscroft, 2009). This paper discusses the 
educational potential of weblogs, a popular mainstream genre of web-based 'social software' (Downes, 2004; Herring, Scheidt, Bonus, \& Wright, 2005; Johnson \& Kaye, 2004; Williams \& Jacobs, 2004); it focuses on using weblogs as tools for reflection on learning. Weblogs are web-based journaling tools which allow for consultation (i.e., reading), registration (i.e., writing), and conversation (i.e., commenting and feedback) (Wijnia, 2004). According to Luehmann (2008), they make thinking visible for critique by oneself as well as by others, and consequently provide rich opportunities for reflection. Unfortunately, due to the relative novelty of weblog technology and its scanty diffusion in formal educational practice, this claim is not backed up with rigorous empirical research. In order to contribute to the much needed body of knowledge on reflective weblog usage in formal education, we conducted an exploratory study on the usefulness of weblogs for reflection within the domain of teacher education. This domain was chosen since reflection on learning is an important constituent of the teacher training curriculum (see e.g., Commission of the European Communities [CEC], 2007; Organisation for Economic Cooperation and Development [OECD], 2005). Moreover, this domain has a large research tradition regarding reflection, learning, and professional development (see e.g., Hatton \& Smith, 1995; Korthagen, 2001). Within this research tradition the use of new technologies for supporting reflection in learning situations is an emerging research topic (see e.g., Kirschner \& Wopereis, 2003; Strudler \& Wetzel, 2005; Van den Berg, 2001). Before we discuss the research questions of this exploratory study in depth, the concepts of reflection, weblogs, and weblog affordances for reflection will be elaborated upon. 


\subsection{Reflection}

Reflection, defined as the mental process of (re)structuring experiences, existing knowledge, or insights (Korthagen \& Wubbels, 1996), is currently a key concept in teacher training and development (CEC, 2007; OECD, 2005). The ability to reflect is regarded essential for both the individual (aspirant) teacher and the teaching community at large. For the individual (aspirant) teacher it is strongly believed that elaborate and ongoing reflection on the learning process is important for initial skill learning and subsequent professional development (Ertmer \& Newby, 1996, Korthagen \& Vasalos, 2005; Schön, 1983, 1987). For the teaching profession at large teachers' distinct reflection skills are considered key ingredients for inducing and guiding educational change and reform (Fullan, 2007; Griffiths, 2000). Although the importance of reflection is well recognized in both teacher education and the teaching profession, teacher training and development programs fail to turn out highly competent reflective practitioners. To a large extent this is due to the complex nature of reflection. Especially deep reflection on professional actions is hard and requires extensive training (Korthagen \& Vasalos, 2005). Teacher training and development programs simply are too short to provide learners with sufficient opportunities to master the reflection skills at a high level. Next to the lack of time in teacher training programs, the quality of reflection instruction can be brought forward as a failure factor for reflection skill learning. Boud and Walker (1998), for instance, mention the negative effects teacher's misconception of reflection can have on acquiring the reflection skill. According to them, misconceptions on the nature of reflection can lead to instrumental or rule-following approaches to reflective activities. This 'recipe following' too often results in mechanistic activities, which inevitably reduces 
learners' motivation for reflective practice and learning. As a result, students often postpone their reflective activities till the moment they have to hand in their reflective writings for some sort of (formative) evaluation by teachers or peers. Although 'stepping out of the process' is regarded an important strategy for reflection (Bennamar, 2004), mounting up reflective writing activities till the end of an apprenticeship period is certainly not.

Even when reflection instruction is well designed and implemented, teacher trainers can be confronted with students who have an aversion towards reflective thinking and writing. Some students perceive reflective writing as a distraction from the learning task at hand and do not associate this activity with working as a teacher. To anticipate this, it is important to show students the surplus value of being an expert reflective practitioner. Since reflection might include the expression of feelings of vulnerability, it is not unusual for students to delay or even abandon reflective writing (Hatton \& Smith, 1995). For reflection instruction to be effective, it is therefore imperative to create a learning environment in which students feel secure.

Reflection involves understanding one's own process of learning. It entails experiencing understanding of oneself as a learner in a variety of contexts. By organizing, monitoring, and evaluating one's learning someone can derive a renewed state of understanding about one's performance (Schön, 1983). Moreover, reflection is an active, intentional, and purposeful process of exploration, discovery, and learning, which is embedded within social interaction. Interactivity is an important condition for gaining multiple perspectives on learning and receiving feedback on one's own performance and understanding (Lin, Hmelo, Kinzer, \& Secules, 1999). Multiple perspectives on student performances can be provided by mentors and teachers by 
means of expert modelling. However, these perspectives can also be presented to the learner or commented upon by fellow students. According to Boud (1999) using fellow students or peers as 'critical friends' in the learning process is a powerful instructional method.

A motley collection of tools exists for supporting reflection (Benammar, 2004). The most popular tools, e.g. portfolios (e.g., Mansvelder-Longayroux, Beijaard, \& Verloop, 2007) and journals or logbooks (e.g., Korthagen, 1999), focus on externalizing and capturing reflective thinking. By committing reflective thinking to paper or computer, it is possible to step out of the (learning) process and allocate time for observing and evaluating preceding performance and learning. Tools such as portfolios and journals are therefore particularly useful for supporting reflection on action. Reflection on action can be defined as 'the active process of making sense of past experiences for the purpose of orienting oneself for current and/or future thought and action' (Ertmer \& Newby, 1996, p. 17; Schön 1983). Ideally this is a spiral process that includes alternating stages of acting, learning from the actions, and improving the action. Korthagen $(1999 ; 2001)$ introduced a five-phase spiral model that describes the reflection on action process. It includes (a) action, (b) looking back on the action, (c) awareness of essential aspects, (d) creating alternative methods of actions, and (e) trail (which is the action phase of a new reflection cycle). Spiral reflection is regarded a basic form of reflection on action and has been extensively used for reflective practice (learning) in teacher education (Benammar, 2004). Reflection on action contrasts with reflection in action, which means that the learner manages 'the process of learning on-line while it is taking place, and constantly 
adjusting and changing [it] as new information is assimilated' (Ertmer \& Newby, 1996, p. 17; Schön, 1983).

Since portfolios and logbooks record reflective thinking, they are also frequently used for assessing the reflection skill. With the advent of the computer, electronic versions of the aforementioned tools emerged. The weblog is just such a promising electronic and web-based variant of a journaling tool; it will be discussed in the next section.

\subsection{Weblogs as tools for reflection}

A weblog or 'blog' is a frequently updated personal website containing dated entries which are displayed in reverse chronological order (Efimova \& Fiedler, 2004;

Schmidt, 2007). Data entries or 'posts' can be easily commented upon, offering opportunities for discussion and feedback. A weblogs is unique in that it integrates the registration, consultation, and exchange of information. These three so-called information patterns are prerequisites for reflection on action, and therefore it is worthwhile to explore the usefulness of this tool in depth.

The usefulness of weblogs for reflection can be discussed in terms of its affordances (see e.g., Wang \& Woo, 2008). According to Norman (1988), affordances refer to 'opportunities for actions; the perceived and actual fundamental properties of technologies that determine the usefulness and the ways they could possibly be used'. Kirschner, Strijbos, Kreijns, and Beers (2004) distinguish three categories of affordances: (a) technological affordances, (b) social affordances, and (c) educational affordances.

Technological affordances refer to the technical usability of a tool. A tool (e.g., an interactive learning environment) must allow for the accomplishment of a task in a 
way that satisfies the user. For a tool that supports reflection tasks this means that it may not hamper the process of registering, consulting, and exchanging knowledge because of technological inadequacy. According to Woo and Wang (2008) important technological affordances of weblogs are the on-line availability and accessibility of the instrument, the user-friendliness of contemporary authoring tools, the opportunities for customization, and the dimension of display of information on a weblog. Through the years weblog tools have evolved into reliable, user-friendly instruments which do not require elaborate computer programming skills. As a result, current weblog users can fully concentrate on writing and reading content (Du \& Wagner, 2006). As for weblogs, the opportunity for customization for instance means that students can modify the interface and embed external sources such as video's and pictures to their (reflective) writings. Interestingly, customization can nourish weblog ownership, an important success factor for educational innovations (see e.g., Kirschner, Wopereis, \& Van den Dool, 2002; Sloep et al., 2006).

Social affordances focus on the exchange of information. They refer to tool features that promote social interaction. As discussed, social interaction is an important precondition for reflection on action because it allows for multiple perspectives on learning and feedback from teachers and peers on student performances. Weblogs allow for commenting on postings and thus interpersonal communication. Since weblogs are web-based tools, the extent of interpersonal communication can be very large. The awareness that a large audience can read and comment upon one's reflective thinking, can have both positive and negative effects on reflection. On the one hand, the idea of global interconnectivity can lead to better thought-through reflection posts by students, which may benefit the quality of 
reflective writing. On the other hand, this awareness may also hinder the expression of personal experiences, because students do not want to expose their vulnerable side. In case global interconnectivity (cf. openness) is not desirable, it is good to know that weblog technology enables small group interaction (for instance, only teacher-learner interaction). It is possible to create a password protected weblog community or let a student decide who can read a specific weblog contribution. Being in charge over one's reflective writings is an important factor for weblog success (cf. ownership).

Educational affordances are 'those characteristics of an artefact that determine if and how a particular learning behaviour could possibly be enacted within a given context' (Kirschner et al., 2004, p. 51). Wang and Woo (2008) mention three educational affordances of weblogs: (a) ownership, (b) developmental processes, and (c) interactivity. In contemporary educational practice students are increasingly responsible for their own learning. This means they should also be in charge of the toolbox that supports their gaining knowledge and skills. In case of weblogs, students are fully responsible for content and interface. They 'own' the tool, since they are allowed to customize the interface, and add, edit, or delete postings and (external) comments. Another educational affordance is the opportunity to display developmental processes. Since a weblog presents reflective writings (posts) in reverse chronological order, it is possible to capture a sequence of learning activities. Moreover, this can be enhanced by the possibility to add keywords (tags) to posts. This functionality allows for categorization and enables students to monitor the acquisition of a specific skill or competence in depth. The last educational affordance is interactivity. We already mentioned social interaction as a feature of social affordance, which focuses on both the learner-teacher and the learner-learner 
relationship (cf. Chou, 2003). In addition to these two kinds of interactivity, Chou (2003) also distinguishes learner-content interaction. According to Wang and Choo (2003) this type of interaction is central to weblogs: students write content and 'interact' with content by reflecting on it. This process can be intensified by social interaction (learner-learner interaction and learner-teacher interaction).

\subsection{Research questions}

The usefulness of weblogs as instruments for reflection on action is central to this study. The usefulness of an artefact can be determined by its usability and utility. The former determinant refers to the technological affordances of an artefact. The latter denotes both the educational and the social affordances of an artefact (Kirschner et al., 2004). The description of weblog affordances in the previous section suggests the potential value of weblogs as instruments for reflection on action. To undergird this suggestion empirically, this study seeks to answer the following research question:

- Are weblogs useful instruments for supporting and promoting reflective practice in a formal educational setting (especially apprenticeship)?

This prompted the following sub questions:

- Do students create reflective content during apprenticeship (do they write reflection posts)? To answer this question, student weblogs were analyzed and time on task was recorded.

- Do students interact and consequently engage in reflective thinking and learning (can we identify learner-learner and learner-teacher interaction (i.e., comments that include (peer) feedback); is peer feedback well distributed among the group members)? To answer this question, comments of peers and teachers were analyzed and time on task was recorded.

- Does weblog usage help to solve problems which are related to reflective practice in formal educational settings (i.e., mounting up reflective writing and the aversion towards reflective writing)? To answer this question time between performance and reflective writing was captured and students were interviewed.

- Do students and teachers perceive weblogs as useful instruments for reflective practice during apprenticeship? To answer this question a questionnaire was administered and students and teachers were interviewed. 
In order to get an ecologically valid answer to the main research question existing groups of students were invited to participate in this study. Since student group size in teacher education varies, it was decided to include both small-sized groups and medium-sized groups in this study. Further, it was decided to restrict access to the weblogs to students and teachers only. Although it was expected that the students' experiences with internet, weblogs, and reflection were equally scant, a questionnaire was administered before the exploratory study started to examine this expectation.

\section{Method}

\subsection{Participants}

Twenty student teachers from two teacher training institutions participated in the study. These students belonged to three separate groups. Seventeen students entered a four year bachelor degree program at a teacher training college (TTC). These students were trained to teach at institutions for secondary (vocational) education. Three students attended a one-year master degree program for secondary school teachers at a university (i.e., pre-service teacher education: PSTE). These students already held a master's degree and were trained to teach in higher general secondary education and pre-university education.

The seventeen TTC-students belonged to two distinct groups: (a) first-year students ( $\mathrm{n}=8$; TTC-1) and (b) third-year students ( $\mathrm{n}=7$; TTC-3). The TTC-1-students were trained to teach geography $(n=2)$, economics $(n=2)$, English $(n=2)$ and history $(n=2)$. They formed a group with respect to general professional skills learning during apprenticeship. The group of TTC-3-students was trained to teach geography $(n=1)$ and history $(\mathrm{n}=8)$. The three PSTE-students were trained to teach geography. 
The PSTE-students were older (mean age 31.7, $S D=2.5$ ) than the TTC-1 and TTC-3-students (mean ages $20.4, S D=3.2$ and $23.5, S D=2.4$ respectively). The population of participants consisted of eight female and 12 male students. The PSTEgroup included two female students and one male student; the TTC-1-group included five female and three male students, and the TTC-3-group consisted of one female student and eight male students.

\subsection{Materials}

\subsubsection{Reflection weblogs}

For each student group (TTC-1, TTC-3, and PSTE), a network of weblogs was created. All weblogs within a network were connected to one another by means of real simple syndication (RSS; Wikipedia, 2009) and links. RSS was used to notify both the teacher and the students of each student's three most recently published reflective writings ('reflection posts'). These notifications were presented in the right margin of the teacher weblog, a weblog that was central to the weblog network in that it provided students with general information and feedback regarding reflective practice. Beside the RSS functionality in the teacher weblog, links to all weblogs were included in the right margin of each student weblog. By adding this functionality students were able to easily consult weblogs of fellow students. Figure 1 represents the interconnectedness of a network of weblogs for a group of students by means of RSS and linking. 


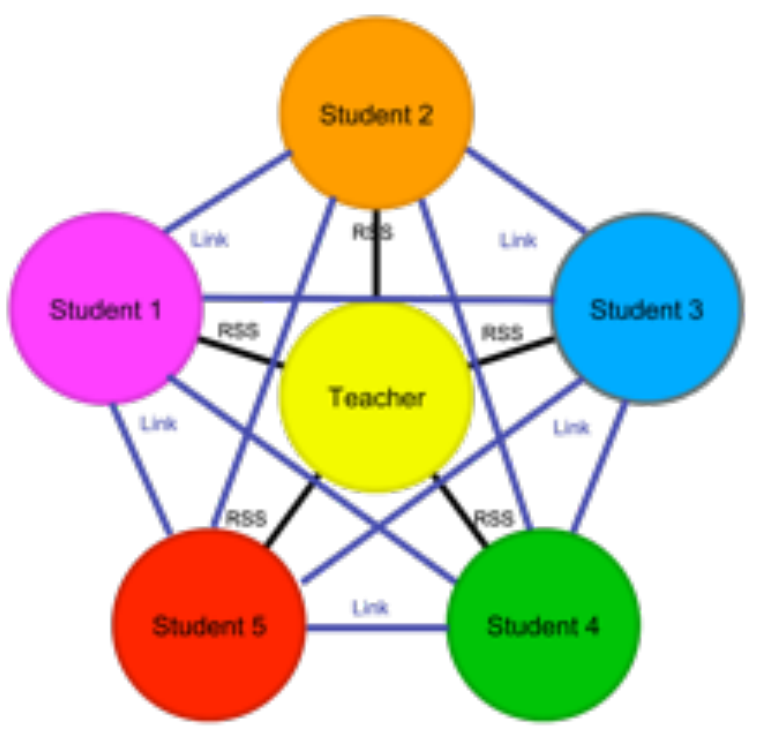

Figure 1. An example of a community of practice for reflective purposes

For writing reflection posts, students used a password protected authoring tool, which was part of the weblog system. Beside the student, the administrator of the research project had access to the authoring tool. Apart from writing contributions, students were authorized to customize their weblog. Students could change colours and fonts and choose their own weblog template. Customization features were offered to the students in order to promote ownership. Another important feature of the weblog was the possibility for students to protect each reflection contribution with a password. By doing so, students were able to decide who could read a particular reflection contribution (for instance only the teacher). Each reflection post could be commented upon. Students were asked to read the contributions of fellow students and provide feedback on the reflection posts. Also the teachers could use this functionality to provide feedback on reflective practice.

Students could add predefined keywords to their reflection posts for categorizing reflective writings. Two category systems were predefined: the TTC- 
students could categorize their postings based on type of competence (i.e., interpersonal, pedagogical, subject knowledge and methodological, organizational, collaboration with colleagues, collaboration with the working environment, and competence for reflection and development; see also Association for the Professional Quality of Teachers, SBL, n.d.). The PSTE-students could categorize their postings according to teacher role (i.e. the professional, the designer, the performer, the educationalist, the colleague). Reflection posts were categorized by adding the predefined keywords (competences of teacher roles) to the reflection posts. Sequences of reflective writings on a certain predefined topic could be selected by clicking on this topic in the margin of the weblog. Students could also use a built-in search engine for seeking information within a student weblog.

In order to help student teachers to write good reflective writings, students were asked to write structured posts. First, student teachers were asked to write down what actually happened (the action). Second, they were asked to write down what according to them was important. Finally, the resolutions or learning wishes had to be identified. More advanced teacher students could add information on their own thoughts and feelings, and subsequently the expected thoughts and feelings of their pupils (see e.g., Korthagen, 1999).

All weblogs were set up by an educational information technology provider. This company used WordPress to create the weblogs for students and teachers. WordPress is a blog publishing system written in PHP and backed by a MySQL database. It is open source software that is distributed under GNU General Public License. 


\subsubsection{Instruction}

Workshop Reflective Writing in Weblogs. The aim of the workshop Reflective Writing in Weblogs was to point out to the student teachers how to write reflective writings (posts) and feedback (comments) in weblogs. The focus of the instruction was on learning reflection skills, feedback skills, and instrumental skills (i.e. handling/ managing a weblog). The instruction consisted of three learning tasks. The learning tasks were so-called 'whole tasks': all aspects of the 'real-life' task were part of the learning task (cf. Van Merriënboer \& Kirschner, 2007). The first learning task was a case study. For this study the students were first asked to watch a teacher in action on video. After watching the video the students were asked to analyze the reflective (weblog) writing of the teacher. Guiding questions were provided to the students. The second learning task was a completion problem. Again the students had to watch a video of a teaching situation. Students received an incomplete reflection report and had to fill in the missing parts of the report on worksheets. After these two tasks the students completed a tutorial that focused on handling the weblog application. The third learning task was a conventional task where students had to reflect on a recent incident that took place during their apprenticeship. The reflective writing had to be written in their personal weblog. A small presentation on reflection, feedback and weblogs preceded the three learning tasks. This information was also presented to the students in a theory book.

Teacher support. The teacher was able to present general information about reflection and feedback on the teacher weblog. Students received feedback on their reflective writings on a regular basis. Feedback was presented to the students by means of commenting. 


\subsubsection{Instruments for data collection}

Questionnaire Experience and Orientation (QEO). The Questionnaire Experience and Orientation consisted of open questions and statements. Questions and statements were formulated to elicit students' experiences with the internet, weblogs, and reflection. The QEO was administered after the introductory workshop. For scoring the statements a five-point Likert-scale was used, where ' 1 ' meant total disagreement and '5' stood for total agreement. An example of a statement was "You can call me a blogger.”

Questionnaire Evaluation Weblogs (QEW). The Questionnaire Evaluation included 63 statement on the weblogs (user-friendly, means for reflection-on-action, et cetera). Further, open questions were formulated to generate information on the number of reflective writings (posts), feedback (comments), time spent on reading and writing. Students and teachers were also asked if there should be a follow-up of the intervention (continuation), if they would use the instrument as a tool in their own teaching practice and if they had any suggestions for improvements. Finally, students and teachers were asked to award marks ( 1 to 10 , where 1 is poor and 10 is excellent) for the idea of using weblogs as instruments for reflection-on-action, the instrument used, and the whole project (the implementation).

Instrument to analyze the reflective posts and comments (IRPC). Both reflective writings (posts) and feedback (comments) were analyzed in depth. The analysis of the content of the posts focused on uncovering (a) topics, (b) competences, (c) depth of reflection, (d) teacher development phase, (e) spiral process, and (f) postponement of writing posts. The analysis of the comments aimed at revealing feedback topics, (b) the nature of the feedback, (c) type of feedback, (c) feedback content, and (d) 'who 
gave feedback to whom'. Information on the latter topic was needed for calculating Freeman's degree centrality measures (Freeman, 1979). With the help of the instrument the posts' topics were listed and other aspects were categorized. For each situation described in the reflective post the main competence focus had to be determined. This focus could be on (a) interpersonal competence, (b) pedagogical competence, (c) subject knowledge and methodological competence, (d) organizational competence, (e) competence for collaboration with colleagues, (f) competence for collaboration with the working environment, and (e) competence for reflection and development (see also Association for the Professional Quality of Teachers, SBL, n.d.). Regarding reflection depth, posts were categorized as 'plain descriptive', when a teacher student just recorded what actually happened, what is considered important, and which resolutions or learning wishes this gives rise to (see Korthagen, 2001). A post was categorized as 'deeply reflective', when feelings were reported and students projected themselves into the role of the pupil in the classroom. The aspect 'teacher development phase' focused on the identification of developmental stages in the reflective writings. These stages are (a) idealistic teacher view, (b) concerns for survival, (c) establishing authority, developing teaching strategies, and adopting the teaching styles of the class teacher, (d) reaching 'plateau', where concerns about control are often replaced with those about pupil's learning, and (e) developing a deeper understanding of teaching and learning (Griffith, 2000). A reflection post was scored as 'part of a spiral process' when the student elaborated on previous actions, consequences, or goals. Finally, when possible the amount of time between the action and the reflection-on-action-post was administered by the instrument. With respect to feedback topics were listed. The nature of the feedback 
was categorized as (a) positive, (b) negative, or (c) neutral. Further, the feedback was typified as (a) corrective, (b) neutral, (c) recognition-affirmative, (d) recognitionsympathy, (e) recognition-sympathy-value, or (f) encouragement. Finally, the feedback content was categorized as (a) solution, (b) suggestion, or (c) questionrequest. As mentioned above with the instrument the interaction was recorded, meaning that 'who wrote comments to whom' was taken down.

Group interviews. Semi-structured group interviews were organized after the intervention to reveal information on usefulness and surplus value of the reflection blogs. Students and teachers were interviewed in groups. The interviewees were also asked to reflect on the project and to give suggestions for improvements.

\subsection{Procedure}

\subsubsection{Data collection.}

This exploratory study started with the workshop Reflective Writing in Weblogs. Immediately after the workshop, the students were asked to fill in the QEO questionnaire. As from then, the students had to reflect on their teaching experiences during an eight week lasting internship. After the internship the students were interviewed as a group and were asked to fill in the QEW questionnaire individually. The IRPC was used to analyze both reflective writings and feedback.

\subsubsection{Data analysis weblog content.}

Two trained raters scored in pairs the content of eight student weblogs by using the IRPC coding system. For each of the eight weblog analyses inter-rater reliability coefficients (Cohen's Kappa) were calculated. Table 1 provides an overview of the coefficients. It shows that the inter-rater agreement ranges from 'fair' to 'almost perfect' (cf. Landis \& Koch, 1977). One rater scored the remaining student weblogs. 
Table 1. Inter-rater reliability (Cohen's Kappa) on content analysis posts and comments

\begin{tabular}{ll}
\hline Weblog contribution & Cohen's Kappa \\
\hline Posts & 0.90 \\
- depth of reflection & 0.94 \\
- teacher development phase & 0.87 \\
- spiral process & \\
Comments & 0.85 \\
- nature of feedback & 0.69 \\
- type of feedback & 0.58 \\
- feedback content
\end{tabular}

Note: Kappa's are based on the analysis of weblog contributions of eight student teachers

\subsubsection{Data analysis questionnaires.}

For all items of the two questionnaires means and standard deviations were

calculated. Non-parametric tests were used to test for differences between the groups.

\section{Results}

\subsection{Previous experiences and orientations}

Before the intervention took place students were asked to report on their experiences with the internet, weblogs, and reflection. With regard to internet use students said to use the internet both for study and private activities. On both type of activities they spent approximately ten hours a week (study 9.8 h., $S D=11.66$; leisure 10.5 h., $S D=12.4)$. The students regarded themselves reasonable experienced internet users (3.4 on a five-point Likert scale; $1=$ total disagreement; $5=$ total agreement; $S D=1.2$ ). With respect to weblog use the students were less experienced. Only one student owned a weblog, but did not keep it up to date (only once a month). Six students occasionally read weblog writings (range: once per month to five times per week) and four students wrote every now and then a comment (range: once every month up to twice a week). Therefore it is no surprise the students did not see themselves as 'bloggers' (1.2 on a five-point Likert scale; $S D=0.5)$. Reflection was recognized as a fairly important skill (3.7 on a five-point Likert scale; $S D=1.2$ ) and the subjects 
regarded themselves reasonably competent in it $(3.4 ; S D=0.9)$. Reflection activities

were not conceived as particularly annoying $(3.2 ; S D=1.2)$ or dull $(3.2 ; S D=1.2)$. For all the above measures no significant differences between the three groups of students were identified.

\subsection{Creating reflective content}

During the eight-week internship the student teachers wrote a total of 162 reflection posts. Interestingly, the PSTE teacher trainer, who was also a secondary school teacher, wrote also four reflection posts. Table 1 shows the total number of contributions, the average number of contributions for each student, and the average number of contributions for each student per week. Besides, the total number of reflection posts and the averages for each group (PSTE, TTC-1, and TTC-3) are presented.

Table 2. Total number of weblog contributions, average numbers per student/teacher during the internship, and average numbers of contributions per student/teacher per week.

\begin{tabular}{|c|c|c|c|c|c|c|}
\hline \multirow[t]{2}{*}{ Group } & \multicolumn{3}{|c|}{ Posts } & \multicolumn{3}{|c|}{ Comments } \\
\hline & $\overline{\mathrm{N}}$ & per student & per week & $\mathrm{N}$ & per student & per week \\
\hline \multicolumn{7}{|l|}{ TTC-1 } \\
\hline - students $(n=8)$ & 98 & $12.25(5.31)$ & $1.53(0.66)$ & 48 & $6.00(5.10)$ & $0.75(0.64)$ \\
\hline - teachers $(n=1)$ & 0 & 0 & 0 & 26 & $26.00(-.--)$ & $3.25(-.--)$ \\
\hline \multicolumn{7}{|l|}{ TTC-3 } \\
\hline - students $(n=9)$ & 27 & $3.00(1.41)$ & $0.38(0.18)$ & 47 & $5.22(3.63)$ & $0.65(0.45)$ \\
\hline - teachers $(n=2)$ & 0 & 0 & 0 & 24 & $12.00(1.41)$ & $1.50(-.--)$ \\
\hline \multicolumn{7}{|l|}{ PSTE } \\
\hline - students $(n=3)$ & 37 & $12.33(6.35)$ & $1.54(0.79)$ & 32 & $10.67(4.16)$ & $1.33(0.52)$ \\
\hline - teachers $(n=1)$ & 4 & $4.00(-.--)$ & $0.5(-.--)$ & 16 & $16.00(-.--)$ & $2.00(-.-)$ \\
\hline \multicolumn{7}{|l|}{ Overall } \\
\hline - students $(n=20)$ & 162 & $8.10(6.16)$ & $.01 \quad(0.77)$ & 127 & $6.35(4.53)$ & $0.79(0.57)$ \\
\hline - teachers $(n=4)$ & 4 & $1.00(2.00)$ & $0.13(0.25)$ & 66 & $16.50(6.66)$ & $2.06(0.83)$ \\
\hline
\end{tabular}

Note: standard deviation between brackets

The total group wrote an average of 1.01 reflective posts a week. The TTC-3 group wrote significantly fewer reflective posts than did the other two groups (mean TTC-3 $=0.38$ vs. TTC- $1=1.53$ and PSTE $\left.=1.54 ; \chi^{2}(2, \mathrm{~N}=20), p<0.01\right)$. The student 
teachers were also asked to make a note of the perceived number of reflection posts they wrote during the internship. With respect to writing reflective posts there was a significant difference between the students perceived and observed (counted) writing scores. The student teachers said they entered on average about two writings a week, while the actual score was about one post a week A t-test provided statistical evidence for this difference on total group level $(t(15)=2.98, p<0.01)$. On group level significant differences between (student) perceived and (actual) counted reflective writings were only found for group TTC-3 $(t(7)=4.14, p<0.01)$.

Since it was impossible to capture the actual time invested in reflective writing, students were asked to record their perceived time investments. Table 3 provides an overview of the time investment of students. In view of the just mentioned observation that they overestimated their frequency of writing, they may also have overestimated their time spent on writing. We have no evidence for this, though, nor to the contrary for that matter.

Table 3. Time investment as perceived by the students

\begin{tabular}{lcccccccc}
\hline & \multicolumn{3}{c}{ Writings (minutes a week) } & \multicolumn{3}{c}{ Reading (minutes a week) } \\
\cline { 2 - 9 } & \multicolumn{2}{c}{ Post } & \multicolumn{2}{c}{ Comment } & \multicolumn{2}{c}{ Own blog } & \multicolumn{2}{c}{ Peer blog } \\
\cline { 2 - 9 } & $M$ & $S D$ & $M$ & $S D$ & $M$ & $S D$ & $M$ & $S D$ \\
\hline TTC-1 (n=8) & 62.50 & 24.03 & 22.83 & 20.50 & 20.83 & 8.01 & 38.33 & 27.14 \\
TTC-3 (n=9) & 37.86 & 14.39 & 17.86 & 9.51 & 8.00 & 10.63 & 18.57 & 9.45 \\
PSTE $(\mathrm{n}=3)$ & 40.00 & 20.00 & 13.33 & 5.77 & 8.33 & 2.89 & 11.67 & 2.89 \\
Total $(\mathrm{n}=20)$ & 47.50 & 21.76 & 18.88 & 13.91 & 12.88 & 10.40 & 24.69 & 20.21 \\
\hline
\end{tabular}

Table 3 shows that the total group of student teachers said they spent (on average) 47.50 minutes a week on writing in their own weblog. But what were the topics the students wrote about? Content analyses with IRPC shows that the reflection posts mainly focused on (a) the interpersonal competence $(n=69$; i.e., skills prerequisite for creating a perfect social climate in the classroom), (b) the organizational competence 
( $n=35$; i.e., skills prerequisite for creating a well-ordered task-focused learning environment), and (c) subject matter knowledge and methodological competent $(\mathrm{n}=28$; i.e., skills prerequisite for designing, implementing, and evaluating learning tasks). Classroom management is frequently mentioned as a subject that needs special attention. This closely fits the developmental phase the student teachers are in. Based on the analyses of the reflection posts it can be concluded that most writings address topics that are related to the 'survival' in the classroom, the second phase in a fivephase teacher development model (Griffith, 2000). However, the TTC-3-group also addresses topics which are related to establishing class authority (the third phase in the model). Regarding the depth of reflection, it can be concluded that the reflection posts of the total group were not profound. In the total group, only 31 percent of the reflection posts are categorized as 'deep reflection'. In the TTC-3-group this percentage is 58, in the TTC-1-group this is 24, and in the PSTE-group the percentage is 23. Also spiral reflection is scarce. Nineteen percent of all reflection posts consisted of posts that were related to other reflection posts. This percentage was relatively high for the TTC-1-group (38\%) and low for the TTC-3-group (4\%). Twenty-three percent of the PSTE postings were classified as part of a spiral process.

\subsection{Social interaction}

An important feature of weblogs is that they allow one to comment on one another's postings. This functionality enables both teacher and peer feedback. During the eightweek internship the students commented upon each others reflective writings and comments. In total, they wrote 127 comments with feedback (see Table 2). On average the students wrote 0.79 comments a week. For the teachers, this was 2.06 . For providing feedback it is necessary to read each others weblogs. On a weekly basis, the 
students spent 12.88 minutes reading their own weblogs and 24.69 minutes reading other students weblogs. Interestingly, some students in the TTC-1-group said they spent considerately more time on reading than others. This explains the large standard deviations in Table 3. The students also indicated they spent time on writing comments. The average 'time-on-task' for writing feedback was 18.88 minutes a week.

The feedback of students was categorized as 'solution' ( $\mathrm{n}=19)$, 'suggestion/ tip' ( $\mathrm{n}=95)$, and 'question/request' $(\mathrm{n}=21)$. The nature (tone) of the feedback comments was positive $(n=75)$, negative $(n=5)$, or neutral $(n=91)$. Further, the type of feedback was corrective $(n=26)$, neutral $(n=29)$, recognition-affirmative $(n=63)$; recognition-sympathy $(n=33)$, recognition-sympathy-value $(n=15)$, or encouraging $(n=5)$.

Since social interaction is an important impetus for learning, it is also interesting to analyze the 'strength' of the social network (the weblog community). Figure 2 depicts the relations between the members of the three student groups. It shows who gives feedback to whom, or in other words how feedback information flows within the student groups. For determining whether a group is 'in balance' the degree centrality can be calculated. For each group we calculated Freeman's degree centrality (Freeman, 1979). Degree centrality is defined as 'the number of links incident upon a node (i.e., the number of ties that a node has).' If a network is directed (as is the case with a weblog network, in which the direction of the information flow is known), two separate measures of degree centrality, namely indegree and outdegree are calculated. Indegree is interpreted as a form of popularity, and outdegree as gregariousness. 



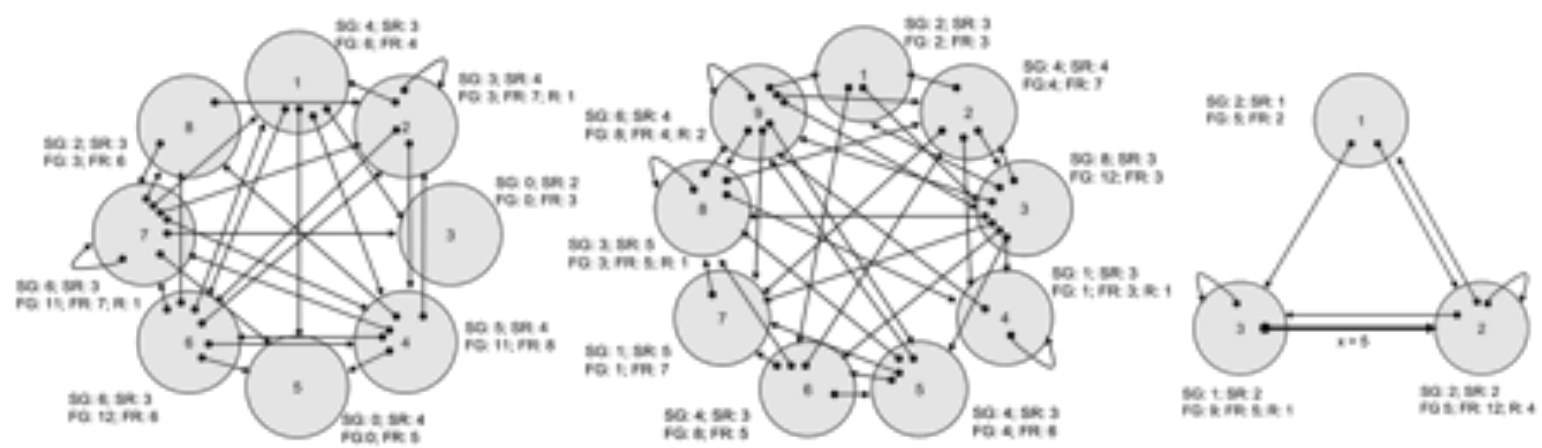

Figure 2. Visualization of peer feedback within the student populations TTC-1; TTC-2; and PSTE, where 'SG' represents the number of students a student gave feedback to; 'SR' represents the number of students a student received feedback from; ' $\mathrm{FG}$ ' is the total number of feedback comments given by a student (i.e., the OutDegree); 'FR' is the total number of feedback comments a student received (i.e., the InDegree), and ' $\mathrm{R}$ ' is the number of feedback responses a student gave in his/her weblog to received feedback. A thin arrow symbolizes five or fewer comments, a thick arrow symbolizes six or more comments. 
The outdegree for the TTC-1-group is 25 percent, the TTC-3-group is 34 percent, and the PSTE-group is 22 percent. The indegree for the TTC-1-group is 9 percent, the TTC-3-group is 10 percent, and the PSTE-group is 47 percent. For the outdegree it can be concluded that the group is in balance: members of all groups give feedback to each other. The indegree for the PSTE-group is relatively large, meaning that someone in this group receives comparatively more feedback than other group members (see Figure 2; FR of student 2 in PSTE-group is 12).

\subsection{Solving reflection problems}

A major problem with reflective practice in educational practice is mounting up reflective writing for (peer) assessment. Do students postpone reflective writing in a weblog community? With the IRPC instrument time between publishing the reflective post and the teaching activity was recorded. The student teachers postponed their reflective writing 3.27 days on average (range 0 to 14.25 days). There were no significant differences between the groups. Table 4 shows the average time delay for reflective writing within the three groups. By removing the outlier (student TTC-1 with a mean delay of 14.25 days), the average delay would be reduced to 2.48 days. Table 4. Time delay writing posts

\begin{tabular}{lcc}
\hline & \multicolumn{2}{c}{ Delay in days } \\
\cline { 2 - 3 } Group & Mean time delay & Range student means \\
\hline TTC-1 & $4.48(5.43)$ & $0-14.25$ \\
TTC-3 $(n=9)$ & $3.10(1.88)$ & $0-05.00$ \\
PSTE $(n=3)$ & $0.71(1.12)$ & $0-02.00$ \\
Overall $(\mathrm{n}=20)$ & $3.27(4.00)$ & $0-14.25$ \\
\hline
\end{tabular}

Note: standard deviation between brackets

The interview and remarks on the QEW questionnaire both indicate that the implementation of a new instrument such as weblogs should be properly introduced at the beginning of a school year. While the TTC-1 group and the PSTE group start 
using the weblogs from the beginning of the apprenticeship period, students of the TTC-3-group start using the instrument in the midst of a large apprenticeship period. This led to a critical attitude towards the use of the instrument. Some of the students questioned the utility of the instrument for third year TTC-students. At this stage "one was able to reflect on action and one doesn't need any kind of tool for learning this skill". Some students also indicated to experience some kind of 'innovation fatigue' which resulted in a relative low appreciation for weblogs as instruments for reflection on action.

\subsection{Perceived usefulness.}

In general, the teacher students were favourable to the idea of using weblogs as instruments for reflection on action. They rated this idea $6.6(S D=1.8)$ on a scale from 1 to 10. The TTC-3-group was least positive (5.6), but not everyone in the TTC-3group held the same opinion, since the standard deviation was high (2.4). However, the teacher students were less positive regarding the implementation of the weblogs. They rated the instrument as $6.0(S D=1.7)$ only. Here there were significant differences between the groups: TTC-1 $(6.7 ; S D=.5)$ en PSTE $(7.3 ; S D=.6)$ gave above par ratings, while the TTC-3-students gave a mark below par $(4.9 ; S D=1.9)$. This group was more sceptic towards the implementation (and thus usefulness) of the instrument. The results of the interview with the TTC-3-group confirmed this finding. The thrust of the interview was that, although the students acknowledged the affordances of the reflection instrument, they did not consider it a useful instrument at this stage in the teacher training curriculum (the third year). This view was not shared by the TTC-3-teachers. 
Interestingly, the results of the QEW questionnaire show that weblogs are perceived as useful instruments for reflection on action by the students ( 3.63 on a five-point Likert scale; $S D=1.15$ ). With regard to opening up their blogs to the world at large, students are reserved: they prefer reflective writings to be visible only to the teacher trainer and their fellow students (4.67 on a five-point Likert scale; $S D=.6$ ). They also want to decide who can read the contributions (4.40 on a five-point Likert scale; $S D=.9$ ), although this view was not shared by every student. One student of the small group mentioned during the group interview that it would be better for learning that a large audience could read and comment on his contributions. Further, all student acknowledged they learn from reading each others reflections ( 3.75 on a five-point Likert scale; $S D=.9)$.

\section{Conclusion}

This study explored the usefulness of weblogs as instruments for supporting and promoting reflection on action in a formal educational setting (i.e., apprenticeship in a teacher training curriculum). Three groups of student teachers were asked to write reflection posts and to provide feedback to peers. Teachers were asked to monitor and stimulate reflective practice within the groups. The usefulness of weblogs was determined by analyzing weblog content, social interaction, reflection problems being solved, and the perceived usefulness of weblogs. No utility measures were made.

Based on the analyses of the weblog content, questionnaires, and interviews, one may conclude that weblogs are suitable for structured reflective writing and feedback. The students wrote a considerable number of reflection posts during the eight-week internship. Unfortunately, these reflections were mainly focused on single critical incidents in the classroom which primarily dealt with survival in the classroom 
(e.g., how to deal with pupils who enter the classroom too late). Although students were informed during the workshop that weblogs are ideal for supporting thematic, sequential, and spiral reflection, these types of reflection were not captured on a large scale.

The opportunity to read each others work, to give feedback, and to learn from different perspectives was highly appreciated by both students and teachers. The fact that (a) most students gave and received feedback and (b) the provision of feedback was fairly distributed amongst the student groups indicated they were socially interactive. Unfortunately, the average number of feedback comments was not as high as expected. A reason for this could be that most students meet fellow students in vivo on a regular basis. In addition to the unexpected low number of feedback comments, large discussions were scarce. Probably discussion forums are more suitable for monitoring and registering intensive discourse (cf. Wang \& Choo, 2008). Although most students recognized that social interaction is important for learning, they were of the opinion that weblog access should be limited to members of a student group. Students consider a safe learning environment more important than a global learning environment where many people can read your reflective writings and provide feedback. However, this study also shows that students want ample comments on their reflective writings. Teacher trainers therefore should consider group-size in case reflection on learning is requested. Paradoxically, the student's need for a safe learning environment seems to be at odds with interconnectivity and interactivity, two of the defining (social) affordances of weblogs and other second generation webbased tools (see Greenhow et al, 2009; McLoughlin \& Lee, 2008; Wang, Woo, \& Zhao, 2009). Giving the students complete control over the openness of weblogs 
might be a solution. As stated earlier, it is possible to create a flexible, passwordprotected reflection environment. What should be brought into the open and what not, should be discussed by teachers and students. Students should be alerted to the dangers of 'total openness' on the internet, a topic that should be part of the media literacy curriculum (Barnes, 2006; Greenhow et al., 2009). The desirable extent of 'openness' should be subject to further research.

When we take a closer look at the problems of contemporary reflection practices in education, it seems that weblogs can help alleviate some of the problems. The delay of reflective writing was considered an important problem in contemporary teacher education. Weblogs (and above all the monitoring of teachers and peers that is involved in social interaction) seem to solve this problem. This is promising, because when students write down their reflection on action on a regular basis this has a positive effect on the quality of reflection (Korthagen, 1999). We expect that the quality of reflection will further increase when the reflective weblog writings on critical incidents in the classroom are used as input for meta-reflection in the (electronic) performance portfolios of students (cf. Mansvelder-Longayroux et al., 2007). Interestingly, one of the students of the PSTE group exactly did this, which was highly appreciated by the teacher trainer. When reflection instruments are perfectly geared to one another, this probably will have a positive effect on the acceptance of weblogs as an instrument for reflection (see e.g., Tosh \& Werdmuller, 2004). This would clear up the resistance some students had regarding the reflection weblogs (some students considered reflective writing in the weblogs as 'additional work'). 
Weblogs seem to be useful instruments for reflection on action. However, it is important to realize that they are 'just' instruments. Probably the most important prerequisite for acquiring good reflection skills is high-quality guided practice.

However, this study shows that good instruments can afford good instruction, practice, and motivation (see also Shoffner, 2009). Further, the study shows that attuning innovations in education is extremely important for success (cf. Kirschner et al., 2002; Sloep et al. 2006). We suggest future research on the use of weblogs as instrument for reflection on action. This research should be longitudinal in nature, so that effects on the reflection ability can also be taken into account ${ }^{1}$.

\section{Acknowledgments.}

This research was conducted within the framework of the project 'Weblogs als Reflectie-Instrument'. The Digital University of the Netherlands is gratefully acknowledged for funding this project (DU project no. 6066).

\section{Notes}

1. In order to get an impression whether the students' reflection ability increased, we asked the teachers to give marks for the students' reflection ability before and after the eight-week internship. Based on these marks it can be said that there is an increase of reflection ability at the end of the internship (even significantly for the TTC-1 group when tested nonparametrically). However, the teachers said they did not know whether this was a result of using weblogs.

\section{Notes on contributors}

Iwan G.J.H. Wopereis is a PhD candidate at the Centre for Learning Sciences and Technologies of the Open University of the Netherlands. His research interests include instructional design, technology enhanced learning, and creativity.

Dr. Peter B. Sloep is a professor of Technology Enhanced Learning at the Centre for Learning Sciences and Technologies at the Open University of the Netherlands, where he directs the Research and Technology Development Programme on Learning Networks. His current research focuses on learning and professional development as well as creativity in online networked environments, dubbed learning networks.

Sybilla H. Poortman is an information professional at Fontys University of Applied Sciences in Sittard, The Netherlands. Her research interests include media literacy, web 2.0 applications in education, mobile learning, and blended learning.

\section{References}

Alexander, B. (March/April, 2006). Web 2.0: A new wave of innovation for teaching and learning? Educause Review, 41(2), 32-44.

Association for the Professional Quality of Teachers, SBL (n.d.). Good quality teachers for good quality education. Retrieved August 23, 2007, from: http:// www.bekwaamheidsdossier.nl/cms/bijlagen/brochure_SBL.pdf 
Barnes, S.B. (2006, September 4). A privacy paradox: Social networking in the United States. First Monday, 9(4). Retrieved June 9, 2009, from http:// firstmonday.org/htbin/cgiwrap/bin/ojs/index.php/fm/article/view/1394/1312

Bennamar, K. (2004). Conscious action through conscious thinking: Reflection tools in experiential learning. Amsterdam, the Netherlands: HvA.

Boud, D. (1999). Situated academic development in professional work: using peer learning. International Journal for Academic Development, 4, 3-10.

Boud, D., \& Walker, D. (1998). Promoting reflection in professional courses: the challenge of context. Studies in Higher Education, 23, 191-206.

boyd, d.m., \& Ellison, N.B. (2008). Social network sites: Definition, history, and scholarship. Journal of Computer-Mediated Communication, 13, 210-230.

Chou, C. (2003). Interactivity and interactive functions in web-based learning systems: A technical framework for designers. British Journal of Educational Technology, 34, 265-279.

Chuang, H.H. (2008). Perspectives and issues of the creation for weblog-based electronic portfolios in teacher education. British Journal of Educational Technology, 39, 170-174.

Commission of the European Communities (2007). Communication from the commission to the council and the European Parliament: Improving the quality of teacher education (Communication No. 392). Brussels, Belgium: Author.

Downes, S. (2004). Educational blogging. Educause Review, 39(5) 14-26.

Du, H.S., \& Wagner, C. (2006). Weblog success: exploring the role of technology. International Journal of Human-Computer Studies, 64, 789-798.

Efimova, L., \& Fiedler, S. (2004, March). Learning webs: Learning in weblog networks. Paper presented at the IADIS International Conference 'Web Based Communities 2004,' Lisbon, Portugal.

Freeman, L.C. (1979). Centrality in social networks. Conceptual clarification. Social Networks, 1, 215-239.

Fullan, M. (2007). The new meaning of educational change (4th. ed.). New York, NY: Teachers College Press.

Griffiths, V. (2000). The reflective dimension in teacher education. International Journal of Educational Research, 33, 539-555.

Greenhow, C., Robelia, B., \& Hughes, J.E. (2009). Learning, teaching, and scholarship in a digital age: Web 2.0 and classroom Research: What path should we take now? Educational Researcher, 38, 246-259.

Hatton, N., \& Smith, D. (1995). Reflection in teacher education: Towards definition and implementation. Teaching \& Teacher Education, 11, 33-49.

Herring, S.C., Scheidt, L.A., Wright, E., \& Bonus, S. (2005). Weblogs as a bridging genre. Information Technology, \& People, 18, 142-171.

Kirschner, P.A., Strijbos, J.W., Kreijns, K., \& Beers, P.J. (2004). Designing electronic collaborative learning environments. Educational Technology, Research \& Development, 52(3), 47-66.

Kirschner, P.A., \& Wopereis, I.G.J.H. (2003). Mindtools for teacher communities: a European perspective. Technology, Pedagogy and Education, 12, 105-124. 
Kirschner, P.A., Wopereis, I.G J.H., Van den Dool, P.C. (2002). ICT3: Information and communication technology for teacher training: Pedagogic benchmarks for teacher education. Utrecht, the Netherlands: Inspectie van het Onderwijs.

Klamma, R., Chatti, M.A., Duval, E., Hummel, H., Hvannberg, E.T., Kravcik, et al. (2007). Social software for life-long learning. Educational Technology \& Society, 10, 72-83.

Korthagen, F.A.J. (1999). Linking reflection and technical competence: the logbook as an instrument in teacher education. European Journal of Teacher Education, 22, 191-207.

Korthagen, F.A.J. (2001). A reflection on reflection. In F.A.J. Korthagen (Ed.), Linking practice and theory: The pedagogy of realistic teacher education (pp. 51-68). Mahwah, NJ: Lawrence Erlbaum Associates.

Korthagen, F.A.J., \& Vasalos, A. (2005). Levels in reflection: Core reflection as a means to enhance professional growth. Teachers and Teaching: Theory and Practice, 11, 47-71.

Korthagen, F.A.J., \& Wubbels, Th. (1996). Characteristics of reflective practitioners: Towards an operationalization of the concept of reflection. Teachers and Teaching; Theory and Practice, 1, 51-72.

Landis, J.R., \& Koch, G.G. (1977). The measurement of observer agreement for categorical data. Biometrics, 33, 159-174.

Luehmann, A.L. (2008). Using blogging in support of teacher professional identity development: A case study. The Journal of the Learning Sciences, 17, 287-337.

Mansvelder-Longayroux, D.D., Beijaard, D., \& Verloop, N. (2007). The portfolio as a tool for stimulating reflection by student teachers. Teaching and Teacher Education, 23, 47-62.

McLoughlin, C., \& Lee, M.J.W. (2008). The three p's of pedagogy for the networked society: Personalization, participation, and productivity. International Journal of Teaching and Learning in Higher Education, 20, 10-27.

Norman, D.A. (1988). The psychology of everyday things. New York. Basic Books.

Organisation for Economic Cooperation and Development (2005). Teachers matter: Attracting, developing and retaining effective teachers. Paris: Author.

Ravenscroft, A. (2009). Social software, Web 2.0 and learning: Status and implications of an evolving paradigm. British Journal of Educational Technology, 25, 1-5.

Schmidt, J. (2007). Blogging practices: An analytical framework. Journal of Computer-Mediated Communication, 12, 1409-1427.

Schoffner, M. (2009). The place of the personal: Exploring the affective domain through reflection in teacher preparation. Teaching and Teacher Education, 25, 783-789.

Schön, D.A. (1983). The reflective practioner. New York, Basic Books.

Sloep, P.B., Van Bruggen, J., Tattersall, C., Vogten, H., Koper, R., Brouns, F., et al. (2006). Innovating education with an educational modelling language: two case-studies. Innovations in Education and Teaching International, 43, 291-301. 
Strudler, N., \& Wetzel, K. (2005). The diffusion of electronic portfolios in teacher education: Issues of initiation and implementation. Journal of Research on Technology in Education, 37, 411-433.

Tosh, D., \& Werdmuller, B. (2004). ePortfolios and weblogs: one vision for ePortfolio development. Retrieved October 19, 2005, from: http://www.eradc.org/papers/ ePortfolio_Weblog.pdf

Van den Berg, E. (2001). An exploration of the use of multimedia cases as a reflective tool in teacher education. Research in Science Education, 31, 245-265.

Van Merriënboer, J.J.G., \& Kirschner, P.A. (2007). Ten steps to complex learning. Mahwah, NJ: Erlbaum.

Wang, Q.Y. , \& Woo, H.L. (2008). The affordances of weblogs and discussion forums for learning: A comparative analysis. Educational Technology, 48(5), 34-38.

Wang, Q., Woo, H.L., \& Zhao, J. (2009). Investigating critical thinking and knowledge construction in an interactive learning environment. Interactive Learning Environments, 17, 95-104.

Wikipedia (2009). RSS. Retrieved August 18, 2009, from http://en.wikipedia.org/wiki/ RSS.

Williams, J.B., \& Jacobs, J. (2004). Exploring the use of blogs as learning spaces in the higher education sector. Australasian Journal of Educational Technology, 20, 232-247.

Wijnia, E. (2004). Understanding weblogs: A communicative perspective. In T. Burg (Ed.), BlogTalks 2.0: The European Conference on Weblogs (pp.38-82). Retrieved August 18, 2009, from http://elmine.wijnia.com/weblog/archives/ wijnia_understandingweblogs.pdf

Xie, Y., Ke, F., \& Sharma, P. (2008). The effect of peer feedback for blogging on college students' reflective learning processes. Internet and Higher Education, $11,18-25$. 